\title{
The Effect of Computer-Assisted Instruction for Elementary School Students in Food Safety and Sanitation Knowledge
}

\author{
Yi-Horng Lai ${ }^{1, a}$ \\ ${ }^{1}$ Oriental Institute of Technology (Taiwan), New Taipei City, Taiwan
}

\begin{abstract}
The purpose of this study is to introduce the graphic presentation food safety and sanitation learning system with parent participation in element school's health and physical education curriculum. The students were divided into four groups: control group, control group with parent participation, learning system group, and learning system group with parent participation. There were three extra variables in this study: learning system, and parent participation. The research data (three exams scores) was obtained before the course, in the middle of the course, and at the end of the course. The results indicate that, first, the estimate of slope of learning system is significantly correlated with parent participation; second, male elementary school students and female elementary school students were similar in the growth rate between each time points; third, the relationship between the initial exam score and the following two exam scores were not significant. Based on the results, it can be concluded that the use of learning system and parent participation were helpful for elementary school students to acquire food safety and sanitation knowledge in the health and physical education curriculum.
\end{abstract}

\section{Introduction}

Schools play an important role in students' health promotion and disease prevention. Since elementary school students tend to form their health knowledge, attitudes and behaviour through school education, it is important for schools to deliver effective health program. [1].

In 2000, Taiwan's Ministry of Education implemented the Nine-Year Integrated Course, and "Health and Sports" is one of the main fields of study. The integration of information technology is a new learning tool for food safety and sanitation, which is an important part of health education.

Computer tailored food safety and sanitation education may be more effective than traditional food safety and sanitation education because messages are tailored to individual behaviour, needs and beliefs. Therefore, the messages are more capable of targeting at individuals and may have stronger motivational effects. Computer tailored food safety and sanitation education has been studied for different dietary behaviours, in different target populations, and in different settings. In recent years, studies [2-4] that assessed the effects of interactive technology in food safety and sanitation education were based on the behaviour change theory. Computer tailored food safety and sanitation education is more likely to be read, remembered, and experienced as it is more personally relevant compared to standard materials. Furthermore, the computer tailored food safety and sanitation education also appears to have a greater effect in motivating people to change their diet, their fat intake in particular, although at present no definite conclusions can be drawn.

The purpose of this study is to explore the effects of the graphic presentation food safety and sanitation education informatics network (Computer Assist Instruction; CAI) with parent participation in elementary school's health and physical education curriculum.

\subsection{The Information technology and food safety and sanitation education}

Computer tailored food safety and sanitation education is an innovative and promising tool to motivate people to make healthy dietary changes. It provides respondents with individualized feedback about their dietary behaviours, motivations, attitudes, norms, and skills and mimics the process of person-to-person dietary counselling. The available evidence indicates that computer tailored food safety and sanitation education is more effective in motivating people to make dietary changes than the traditional food safety and sanitation information, especially for reduction of dietary fat. The effectiveness of computer tailoring has been attributed to the fact that individualized feedback commands greater attention, is processed more intensively, contains less redundant information, and is appreciated better than more general intervention materials. Interactive technology offers good opportunities for the application of computer tailored food safety and sanitation education,

\footnotetext{
a Corresponding author: FL006@mail.oit.edu.tw
} 
and some studies of web-based computer tailoring have shown promising results. [5].

The results of Oenema, Brug, and Lechner's study [6] indicated that interactive, web-based computer-tailored food safety and sanitation education can lead to changes in determinants of behaviour. Food safety and sanitation educators are encouraged to explore the opportunities and challenges of these new technologies to enhance their work [7]. Brug, Steenhuis, Assema, and Vries's study [2] pointed out that computer-tailored food safety and sanitation information is a promising means of stimulating people to change their diet toward dietary recommendations.

Bensley, Anderson, Brusk, Mercer, and Rivas's study [8] claimed that Internet food safety and sanitation education was a viable alternative to traditional food safety and sanitation education for increasing fruit and vegetable consumption in some women, infants, and children clients. Besides, food safety and sanitation education through the telehealth service resulted in positive effects on the risk factors for metabolic syndrome, nutrient intake, and dietary habits [3]. In Tyrovolasa, Tountasb, Polychronopoulosa, and Panagiotakos's study [4], active food safety and sanitation policy and enhancement of food safety and sanitation services within the public health care system can contribute to improved health and quality of life among older populations. The food guidance system provides the basis for the food guidance presented in the American Red Cross food safety and sanitation course, "Better Eating for Better Health", and in "Dietary Guidelines and Your Diet", which is a series of bulletins developed by USDA to help consumers use the Dietary Guidelines [9].

\subsection{The parent participation and food safety and sanitation education}

Niemeiera, Hektnerb, and Enger's study [10] mentioned that weigh-related health interventions with parent participation could more effectively reduce body mass indexes of child and adolescent participants. In addition, longer interventions that include parent participation appear to have greater success. Suggestions for future research and related interventions are provided. Parents who participated in the intervention increased the scores on the food safety and sanitation knowledge test, and there also was a significant association between degree of family involvement, higher grain servings, and lower cholesterol intake [11].

\section{Methods}

The sample of this study was students of an elementary school in Taiwan. The participants came from four classes, and they were assigned in four groups respectively. The four groups were: control group, control group with parent participation, learning system group, and learning system group with parent participation. The research framework is shown in Figure 1 .
The Latent Growth Model of this study is illustrated in Figure 2. Learning system group was the group (class) that applied the graphic presentation food safety and sanitation education system in the four-week food safety and sanitation education.

Learning system group with parent participation was the group (class) that applied the graphic presentation food safety and sanitation education system in the fourweek food safety and sanitation education. Each parent was given a guide book and had the access to the feedback system for this graphic presentation food safety and sanitation education program. Students were required to do homework with the graphic presentation food safety and sanitation education system with their parents.

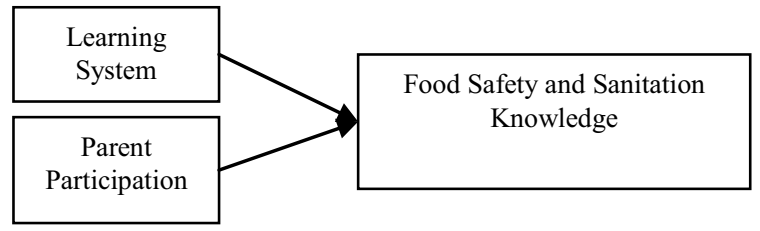

Figure 1. Research framework of this study.

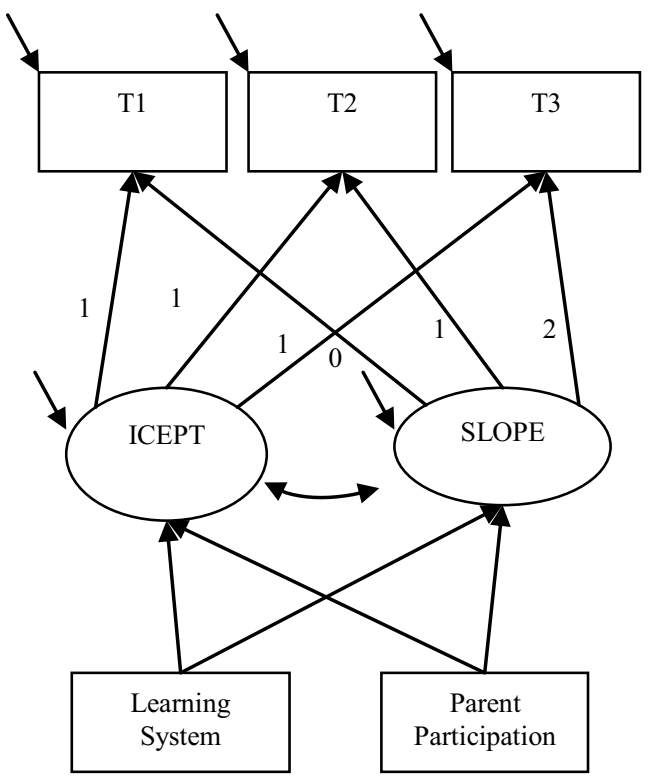

Figure 2. The latent growth model of the effect of food safety and sanitation education system for elementary school students in food safety and sanitation knowledge.

Control group was the group (class) that did the fourweek food safety and sanitation education by traditional teaching method. This group did not involve the graphic presentation food safety and sanitation education system. Control group with parent participation was the group (class) that did the four-week food safety and sanitation education by the traditional teaching method. Each parent was given a guide book and the access to the feedback system. Students were required to do food safety and sanitation education homework by the traditional method with their parents.

The 3 exam scores (T1, T2, and T3) were obtained before the course, in the middle of the course, and at the end of the course. The questions on the three exams were 
based on the learning materials of the four-week food safety and sanitation education of health and physical education curriculum [12].

\subsection{Research data}

124 students of Linong elementary school participated in this study. The data of this study was collected by Y.Y. Chu for the research: The Food Safety and Sanitation Education Information System (Research Project ID is NSC93-2516-S-034-001). This research was completed on July, 31, 2005. Data in this present study was obtained from Survey Research Data Archive (SRDA) [12] (Table 1).

There were four groups in this study: control group (learning system $=0$, parent participation $=0$ ), control group with parent participation (learning system $=0$, parent participation=1), learning system group (learning system $=1$, parent participation $=0$ ), and learning system group with parent participation (learning system=1, parent participation $=1$ ). The 3 exam scores on food safety and sanitation knowledge (T1, T2, \& T3) were obtained at 3 time points before and after the learning system was used.

There were three extra variables in this study: learning system, and parent participation, and they were all binary variables. Learning System $=1$ means using the learning system; Learning System $=0$ means not using the learning system. Parent Participation=1 means learning with parent participation, and Parent Participation $=0$ means learning without parent participation.

There were a total of 59 female students $(47.58 \%)$ and 65 male students $(52.42 \%)$. There were 17 male students and 14 female students in the control group; there were 16 male students and 15 female students in the control group with parent participation; there were 17 male students and 14 female students in the learning system group; and there were 16 male students and 15 female students in the learning system group with parent participation. Each group all had 31 students (Table 1).

Table 1. Data Summarize of the research.

\begin{tabular}{|c|c|c|c|}
\hline & & $\mathbf{N}$ & $\mathbf{\%}$ \\
\hline Gender & Female & 59 & 47.58 \\
\hline & Male & 65 & 52.42 \\
\hline Group & Control Group & 31 & 25.00 \\
\hline & $\begin{array}{c}\text { Control Group with Parent } \\
\text { Participation }\end{array}$ & 31 & 25.00 \\
\hline & Learning System Group & 31 & 25.00 \\
\hline Total & $\begin{array}{c}\text { Learning System Group } \\
\text { with Parent Participation }\end{array}$ & 31 & 25.00 \\
\hline & & 124 & 100.00 \\
\hline
\end{tabular}

\subsection{Data analysis}

The data was analysed with latent growth modelling by using the Mplus 7 software and R 3.2.3. Latent growth modelling is a statistical technique used in the structural equation modelling framework to estimate growth trajectory. It is a longitudinal analysis technique to estimate growth over a period of time.
Latent Growth Model represents repeated measures of dependent variables as a function of time and other measures. The relative standing of an individual at a specific time point is modelled as a function of an underlying process, the parameter values of which vary randomly across individuals. Latent Growth Curve Methodology can be used to investigate systematic change, or growth, and inter individual variability in this change. A special topic of interest is the correlation among the growth parameters, the so-called initial status and growth rate, as well as their relation with time varying and time invariant covariates [13].

\section{Results}

The relationship between time points and the average of exam scores are shown in Table 2.

Table 2. Data summarize of the scores in three time points.

\begin{tabular}{|l|c|r|r|r|c|}
\hline & N & \multicolumn{1}{|c|}{ Mean } & \multicolumn{1}{c|}{ S.D. } & \multicolumn{1}{c|}{ Low } & High \\
\hline Time 1 & 124 & 11.63 & 1.07 & 9.00 & 14.00 \\
\hline Time 2 & 124 & 13.87 & 1.86 & 9.00 & 17.00 \\
\hline Time 3 & 124 & 13.80 & 1.91 & 10.00 & 17.00 \\
\hline
\end{tabular}

As for the model fit information of this study, ChiSquare Test of model fit was $57.296(\mathrm{df}=4)$, RMSEA was 0.328 , and CFI was 0.626 . The estimate of the effect of learning system, and parent participation were found in Table 3 and Table 4. The intercepts of the estimate of use of learning system, and parent participation were not different. The 4 groups (control group, control group with parent participation, learning system group, and learning system group with parent participation) in this study were similar at the initial time point.

The estimates of fixed and random parameter for latent growth curve of this study were displayed in Table 3. It can be found that the estimate of intercept mean and slope mean were 3.060 (p-value <0.001) and 1.777 (pvalue $<0.001$ ). But the estimate of relationship between intercept and slope was -0.004 , P-Value was 0.972 . The relationship between intercept and slope was not significant. It means that the scores were higher than the previous time. Besides, no matter what the initial score is, students could all perform better in the following exams.

Table 3. Fixed and random parameter estimates for latent growth curve of this study.

\begin{tabular}{|l|l|r|r|r|}
\hline & & Estimate & \multicolumn{1}{|c|}{ S.E. } & \multicolumn{1}{c|}{ P-Value } \\
\hline Intercept & Mean & 3.060 & 0.166 & $<0.001$ \\
\hline & Variance & 0.134 & 0.208 & 0.519 \\
\hline Slope & Mean & 1.777 & 0.098 & 0.007 \\
\hline & Variance & 0.029 & 0.090 & 0.750 \\
\hline
\end{tabular}

Table 4 shows that the relationship between the estimate of slope of learning system and parent participation was significant $(\mathrm{P}-\mathrm{value}<0.05)$. The estimate of slope of factor of learning system was 0.385 , and the estimate of slope of factor of parent participation was 0.429 . The growth rate of each exam time was positively correlated with the use of learning system and parent participation. The score of elementary school 
students that used food safety and sanitation education information system was higher than those who did not use food safety and sanitation education information system by 0.385 points in each growth time. The score of elementary school students with participating parents was higher than those without participating parents by 0.429 points in each growth time. Male elementary school students and female elementary school students were similar in slope (the growth rate between each time).

Table 4. The effect of learning system, and parent participation.

\begin{tabular}{|l|l|r|r|r|}
\hline & & Estimate & \multicolumn{1}{c|}{ S.E. } & P-Value \\
\hline Intercept & Learning System & 0.136 & 0.168 & 0.419 \\
\hline & $\begin{array}{l}\text { Parent } \\
\text { Participation }\end{array}$ & 0.183 & 0.169 & 0.279 \\
\hline Slope & Learning System & 0.385 & 0.100 & $<0.001$ \\
\hline & $\begin{array}{l}\text { Parent } \\
\text { Participation }\end{array}$ & 0.429 & 0.100 & $<0.001$ \\
\hline
\end{tabular}

\section{Conclusions}

In recent years, computer applications have emerged as a viable means of gathering and disseminating food safety and sanitation information. Both stand-alone and on-line applications are being used to provide information on in the food safety and sanitation education for the public, paraprofessionals, and professionals. While the use of online communication applications such as multimedia and electronic discussion groups are just emerging as important tools among food safety and sanitation educators, the exponential growth of the Internet and the World Wide Web (WWW) are making these technologies more and more accessible. Food safety and sanitation educators are encouraged to explore the opportunities and cope with challenges of these new technologies to enhance their work.

The use of learning system was helpful for elementary school students to gain more food safety and sanitation knowledge, and this result was consistent with Brug, Oenema, and Campbell [5], Oenema, Brug, and Lechner [6], Brug, Steenhuis, Assema, and Vries [2], Park, Yang, and Kim [3], Tyrovolasa, Tountasb, Polychronopoulosa, and Panagiotakos [4]. Parent participation was helpful for elementary school students to learn more food safety and sanitation knowledge, and this result was the same as Niemeiera, Hektnerb, and Enger [10] and Hopper, Munoz, Gruber, MacConnie, Schonfeldt, and Shunk [11]. Besides, the initial score did not affect students' subsequent performances.

Finally, the learning of food safety and sanitation knowledge will be cultivated by both of the using of CAI (such as graphic presentation food safety and sanitation education system) and parent participation. Teachers could enhance the result of health education with computer learning system and parent support. CAI could be used as assistant teaching materials of food safety and sanitation education. Students could study with CAI on internet by themselves. CAI could reduce the time and expense of resource actual-food practicing. Furthermore CAI can also improve learning efficiency of schoolchildren to achieve balance dietary behaviour.
It can be concluded that the acquisition of food safety and sanitation knowledge can be cultivated by both CAI (such as graphic presentation food safety and sanitation education system) and parent participation. Teachers can enhance the effectiveness of health education with computer learning system and parent support. CAI can supplement teaching materials of food safety, while parents' involvement can help students to achieve better in the learning system. To sum up, this paper has found that the use of CAI with parent participation can effectively improve the food safety and sanitation education in elementary school.

\section{Acknowledgments}

This study is based in part on data from the Survey Research Data Archive (SRDA) provided by the Academia Sinica. The interpretation and conclusions contained herein do not represent those of Survey Research Data Archive (SRDA) or Academia Sinica.

\section{References}

1. V.A. Ubbes, R.R. Cottrell, J.A. Ausherman, J.M. Black, P.C. Wilson, \& J. Snider, Professional Preparation of Elementary Teachers in Ohio: Status of K-6 Health Education. Journal of School Health 69(1), 17-21 (1999)

2. J. Brug, I. Steenhuis, P.V. Assema, \& H.D. Vries, The Impact of a Computer-Tailored Food safety and sanitation Intervention. Preventive Medicine 25, 236242 (1996)

3. S.Y. Park, Y.J. Yang, \& Y. Kim, Effects of Food safety and sanitation Education Using a Ubiquitous Healthcare (u-Health) Service on Metabolic Syndrome in Male Workers. Korean Journal of Nutrition 44(3), 231-242 (2011)

4. S. Tyrovolasa, Y. Tountasb, E. Polychronopoulosa, \& D. Panagiotakos, a Parametric Model of the Role of Nutritional Services within the Health Care System, in Relation to Cardiovascular Disease Risk among Older Individuals. International Journal of Cardiology 155(1), 110-114 (2012)

5. J. Brug, A. Oenema, \& M. Campbell, Past, Present, and Future of Computer-Tailored Nutrition Education. The American Journal of Clinical Food safety and sanitation 77(4), 1028-1034 (2003)

6. A. Oenema, J. Brug, \& L. Lechner, Web-Based Tailored Nutrition Education: Results of a Randomized Controlled Trial. Health Education Research 16(6), 647-660 (2001)

7. K.M. Kolasa, \& M.G. Miller, New Developments in Nutrition Education Using Computer Technology. Journal of Food safety and sanitation Education 28(1), 7-14 (1996)

8. R.J. Bensley, J.V. Anderson, J.J. Brusk, N. Mercer, \& J. Rivas, Impact of Internet vs Traditional Special Supplemental Nutrition Program for Women, Infants, and Children Nutrition Education on Fruit and Vegetable Intake. Journal of the American Dietetic Association 111(5), 749-755 (2011) 
9. F.J. Cronin, A.M. Shaw, S.M. Krebs-Smith, P.M. Marsland, \& L. Light, Developing a food guidance system to implement the dietary guidelines. Journal of Nutrition Education 19(6), 281-302 (1987)

10. B.S. Niemeiera, J.M. Hektnerb, \& K.B. Enger, Parentparticipation in weight-related health interventions for children and adolescents: A systematic review and meta-analysis. Preventive Medicine 55(1), 3-13 (2012)

11. C.A. Hopper, K.D. Munoz, M.B. Gruber, S. MacConnie, B.S. Schonfeldt, \& T. Shunk, A SchoolBased Cardiovascular Exercise and Nutrition
Program With Parent Participation: An Evaluation Study. Children's Health Care 25(3), 221-235 (1996)

12. Y.Y. Chu, The Graphic Presentation Food safety and sanitation Education Informatics Network. The Survey Research Data Archive. Retrieved July 18, 2012

https://srda.sinica.edu.tw/search/gensciitem/1025 (2007)

13. K.J. Preacher, A.J. Wichman, R.C. MacCallum, \& N.E. Briggs, Latent Growth Curve Modelling. Structural Equation Modelling. A Multidisciplinary Journal 19(1), 152-155 (2012) 